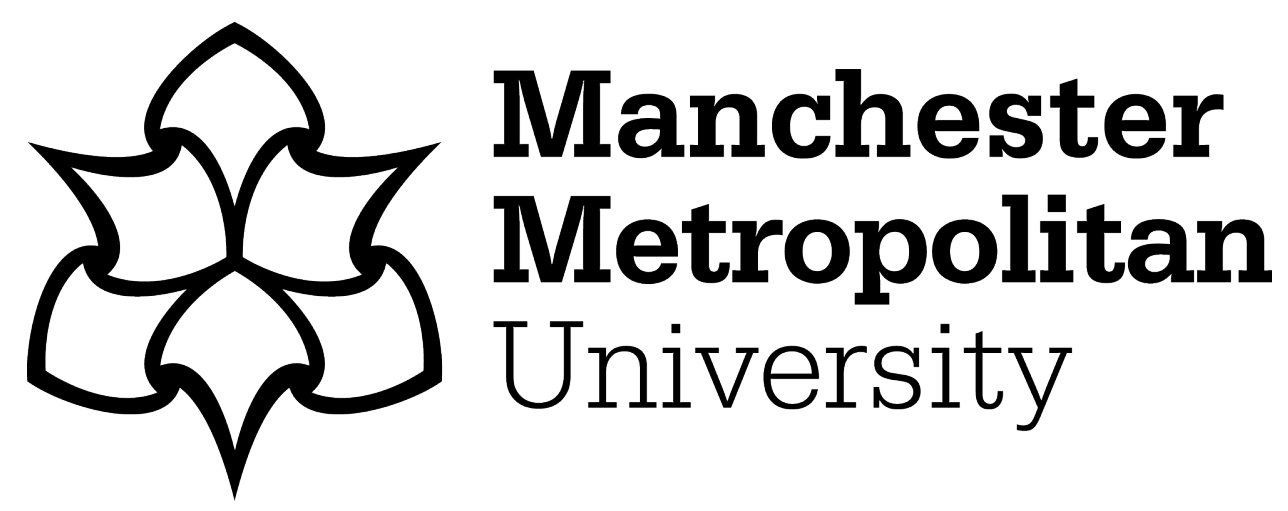

Badwan, Khawla (2018) Effective Classroom Strategies. In: The TESOL Encyclopedia of English Language Teaching. John Wiley \& Sons. ISBN 9781118784235

Downloaded from: https://e-space.mmu.ac.uk/618856/

Version: Accepted Version

Publisher: John Wiley \& Sons

DOI: https://doi.org/10.1002/9781118784235.eelt0179

Please cite the published version 


\title{
Effective Classroom Strategies
}

\author{
KHAWLA BADWAN
}

\section{Framing the Issue}

Employing effective classroom strategies has been one of the main goals underpinning the different language-teaching methods, approaches, and pedagogies since the 1940s. The notion of effectiveness has been strongly linked with the different views of what language is, how teaching should be done, who is a good teacher/ learner, what roles should teachers and learners have in the classroom, and what the relationship between the classroom and the outside world should be (in other words, what the purpose of classroom instruction should be). In addition, the "effectiveness" of classroom strategies can be measured against a long list of factors depending on how the purpose of classroom instruction is perceived by the different educational stakeholders (teachers, parents, educationalists, students, etc.). As a result, the effectiveness of classroom strategies can be measured, among many other factors, against whether or not (a) they allow the students to achieve highly on summative assignments, (b) they develop important skills that students will need to use in out-of-class settings, and (c) they make the students enjoy the process of learning and therefore become key developing practitioners of learning (Allwright \& Hanks, 2009).

On the other hand, language teachers continue to aspire to employ what they would refer to as "effective classroom strategies," but are more likely to be faced with differing perspectives regarding whether or not what they do is effective. This entry traces the historical development of classroom practices as shaped by the different teaching pedagogies, then offers some insights into what can be seen as effective, flexible, and inclusive classroom strategies without aiming to present an exhaustive list or an immediate recipe.

\section{Making the Case}

Over the years, the effectiveness of classroom strategies has been tied to the overall aim of language teaching. A whistle-stop tour of language-teaching history since the 1800 s indicates that the differing perspectives on the nature of language 
teaching and learning have impacted on classroom practices. In the commonly criticized "grammar-translation" method, effective classroom strategies entailed enabling the students to translate sentences from the target language to their mother tongue (and vice versa) as well as being able to adhere to the structural, syntactic rules of the target language. Failing to achieve these objectives ultimately meant questioning the efficiency of classroom strategies which mainly focused on written accuracy and the memorization of vocabulary lists with translated equivalents. In pursuit of "a saner, more rational, and more practical approach" to language teaching (Howatt, 1984, p. 129), the rise of the direct method and audiolingualism took the notion of efficiency to a different level as both approaches placed emphasis on oral accuracy over the fluency and flexibility required for authentic communication. Consequently, classroom strategies were framed around drills, demonstrations, objects and pictures, graded tasks, controlled dialogues, correction of pronunciation, and banning classroom use of learners' first language(s). Responding to the efficiency of these methods and their associated classroom strategies, "some observed that students could produce sentences accurately in a lesson, but could not use them appropriately when genuinely communicating outside of the classroom" (Larsen-Freeman \& Anderson, 2011, p. 115). This provided a platform for a new approach that swept the language teaching industry: the communicative language teaching (CLT) approach, where the aim of classroom instruction was to nurture communicative competence through pair and groupwork activities, games, songs, and information-gap and other learnercentered exercises. Even within this approach different streams of thought emerged as to what is more effective for promoting communicative competence: teaching how to use the language through textbooks that provide explicit instruction as a prerequisite of communication ("weak CLT"), or assuming that knowledge of language use is not a prerequisite and can therefore be developed as a result of communication ("strong CLT") (Howatt, 1984). This divide led to another question as to whether or not using language-teaching textbooks is an effective classroom strategy, because some viewed language learning as essentially a social activity where meanings are negotiated. Although this view was out of favor for years as it attacked the commodification of language teaching through selling textbooks, it seems to be returning in the form of "Dogme Language Teaching" and other forms of critical pedagogy.

In order to balance the limitations of the "weak" and "strong" forms of CLT and in pursuit of more effective strategies, task-based language teaching was introduced as a refinement of CLT and a reaction to its weak form which embraces the PPP (presentation, practice, production) teaching strategy. With task-based teaching becoming a new "fad," the focus was on introducing tasks as contexts for activating the acquisition process and promoting learning. The tasks emphasized the authentic nature of communication and introduced new ways to measure the efficiency of classroom strategies: how authentic the tasks are, and the extent to which they equip students with the skills required for effective and successful in- and out-of-class communication. The strategies 
associated with task-based language teaching involved using pedagogical and authentic tasks which include cognitive processes such as listing, sorting, comparing, problem-solving, creative tasks, and talking about personal experiences as well as language functions such as instructions, suggestions, and apologizing.

In addition to the above-mentioned methods and approaches, other "humanistic" and "holistic" approaches to language teaching were introduced, such as the "Silent Way," Suggestopedia, community language learning, and the total physical response. Effective classroom strategies in light of these approaches entailed seeing the learner as a whole human being whose emotional, physical, and psychological states need to be attended to during the process of learning. These approaches arose as a response to reducing the human to a language learner while ignoring the holistic nature of the learning process and hence reinforcing the importance of the learning environment.

Other voices have called for moving beyond methods and approaches and proposed what are called "post-method approaches" to language teaching in order to liberate classroom practices from monolithic molds imposed by certain methods or approaches (Prabhu, 1990). Based on this, a postmodern pedagogy was proposed by Kumaravadivelu (2001) and linked the effectiveness of teaching with providing context-sensitive education that liberates both teachers and learners and nurtures identity formation and social transformation. These views became more prominent in the language-teaching literature following the "social turn" in applied linguistics (see Block, 2003), which emerged as a critique of "universalist" accounts of language learning and led to recognizing the importance of the learner's voice because, after all, "language learners are not just communicators and problem solvers, but whole persons with hearts, bodies, and minds, with memories, fantasies, loyalties, identities. Symbolic forms are not just items of vocabulary or communication strategies, but embodied experiences, emotional resonances, and moral imaginings" (Kramsch, 2006, p. 251). In light of these perspectives, effective classroom strategies are those that recognize the complexity of the classroom (Tudor, 2001) and the multi-faceted nature of learners' and teachers' brought-about and brought-along identities (see Baynham, 2015).

In spite of the more recent bottom-up strategies to transform classrooms into spaces where teachers are liberated from the constraints of methods and learners are liberated from reductionist approaches to learning and teaching, real classrooms in many parts of the world are still controlled by rigid top-down policies. Such policies have different ways of measuring the effectiveness of classroom strategies, such as learners' achievement tests, parents' satisfaction, or the ranking and reputation of educational institutions. Ultimately, these factors affect the performance of teachers, who are constantly required to meet different, and sometimes conflicting, institutional and non-institutional expectations. That is why the notion of "effective classroom strategies" continues to be a contested one. 


\section{Pedagogical Implications}

Evidently, many language teachers are faced with the challenge of how to determine what is effective and what is not when deciding on their classroom strategies. Fundamentally, the choices made are most likely going to be underpinned by certain perspectives and conceptualizations regarding the purpose of classroom instruction and its relationship with life outside the classroom walls. Since classrooms are complex meeting places where identities and needs are co-constructed, effective classroom strategies need to embrace both inclusivity and flexibility in order to meet the expectations of the different stakeholders involved in the teaching and learning process. This section offers some principles for inclusivity and flexibility as tenets for effective classroom strategies.

First, language teachers need to view classrooms as "communities of practice" where identities are (re)shaped by participation and non-participation in various activities (Wenger, 1998). Teachers are key players in shaping these communities, and learners respond differently to reflect their needs, views, and expectations. When learners feel that they are part of a community, they will be encouraged to "speak as themselves," and "feel involved and motivated to communicate and thus to engage themselves in the process of learning and using the language" (Ushioda, 2011, p. 17). By engaging the learners in the learning and teaching process as co-practitioners who are capable of taking learning seriously (Allwright \& Hanks, 2009), teachers embrace both inclusivity and flexibility, which can then help them reach agreements on how to shape the learning process around the different expected outcomes. This can also give teachers the opportunity to discuss the different strategies they would like to use in their classrooms and negotiate and justify the use of these strategies to explore how effective they are from the perspective of their learners (co-practitioners).

Second, language teachers need to address the complexity of their classrooms by "look[ing] at these classrooms as entities in their own right and explor[ing] the meaning they have for those who are involved in them in their own terms" (Tudor, 2001, p. 9). This, on the one hand, allows teachers to acknowledge learners' individualities and capacities. On the other, it calls for more ecological approaches to learning and teaching in order to decipher the relationship between learners and their environment (van Lier, 2000). A complex system does not have a fixed initial and end state. This means that language teachers need to be flexible about their classroom practices, and this flexibility means responding to internal and external environments affecting the learning process. While this can pose a challenge for novice teachers who find it feels safer to plan an initial and end state for their classrooms, this flexibility allows teachers and learners to develop dialogue as a means of expressing their becoming in the world, an identity (trans)formation process that takes the objectives of teaching and learning to a higher level of self-construction.

Third, by applying the above two principles, language teachers can develop classroom strategies based on ecological considerations that imply using eclectic approaches to language teaching. In other words, they will take part in the "there 
is no best method/strategy/practice" debate (Prabhu, 1990). In order for this to happen, teachers need to know their teaching contexts and the factors that influence them for the sake of developing context-sensitive strategies. The more context-sensitive classroom strategies are, the more authentic and effective they will be for language learners. That said, there will be learners who aspire to more global identities that transcend their local possibilities. That is why classroom strategies based on dialogue offer the needed flexibility and inclusivity which would ultimately enhance the effectiveness of classroom strategies.

SEE ALSO: Grammar-Translation Method; Independent Language Learners in ESOL; Learner Characteristics, Individual Learner Differences, and Learner Role; Needs Analysis; Parameters for Critiquing Appropriate Methodology

eelt0153

eelt0202

eelt0214

eelt0200

spi0463

\section{References}

Allwright, D., \& Hanks, J. (2009). The developing language learner: An introduction to exploratory practice. Basingstoke, England: Palgrave Macmillan.

Baynham, M. (2015). Identity: Brought about or brought along? Narrative as a privileged site for researching intercultural identities. In F. Dervin and K. Risager (Eds.), Researching identity and interculturality (pp. 67-88). London, England: Routledge.

Block, D. (2003). The social turn in applied linguistics. Edinburgh, Scotland: Edinburgh University Press.

Howatt, A. (1984). A history of English language teaching. Oxford, England: Oxford University Press.

Kramsch, C. (2006). From communicative competence to symbolic competence. The Modern Language Journal, 90, 249-52.

Kumaravadivelu, B. (2001). Toward a postmethod pedagogy. TESOL Quarterly, 35(4), 537-60.

Larsen-Freeman, D., \& Anderson, M. (2011). Techniques and principles in language teaching (3rd ed.). Oxford, England: Oxford University Press.

Prabhu, N. S. (1990). There is no best method-why? TESOL Quarterly, 24(2), 161-76.

Tudor, I. (2001). The dynamics of the language classroom. Cambridge, England: Cambridge University Press.

Ushioda, E. (2011). Motivating learners to speak as themselves. In G. Murray, X. Gao, \& T. Lamb (Eds.), Identity, motivation and autonomy in language learning (pp. 11-24). Clevedon, England: Multilingual Matters.

Van Lier, L. (2000). From input to affordance: Social-interactive learning from an ecological perspective. In J. P. Lantolf (Ed.), Sociocultural theory and second language learning. Oxford, England: Oxford University Press.

Wenger, E. (1998). Communities of practice: Learning as a social system. Systems thinker, 9(5), 2-3. 
Please note that the abstract and keywords will not be included in the printed book, but are required for the online presentation of this book which will be published on Wiley's own online publishing platform.

If the abstract and keywords are not present below, please take this opportunity to add them now.

The abstract should be a short paragraph upto 200 words in length and keywords between 5 to 10 words.

\begin{abstract}
Employing effective classroom strategies has been one of the main goals underpinning the different language-teaching methods, approaches, and pedagogies since the 1940s. As it stands, the notion of "effectiveness" is contested as it is determined by and measured against differing sets of factors. The TESOL and applied linguistics literature has, over the years, documented the rise and fall of many methods and approaches which provided different visions for what effective classroom strategies should aim at and achieve. More recent discussions have advocated the need for flexibility and inclusivity in order to negotiate the effectiveness of classroom strategies with the different educational stakeholders, while giving more attention to the role of learners in this process.
\end{abstract}

\title{
KEYWORDS
}

ESL/EFL, Language in the Classroom, Language teaching methods, complexity in the language classroom, inclusivity and flexibility, learners' voice, postmethod pedagogy 


\section{Author Query}

AQ1 Please can you check and let us know if you are fine with your affiliation as listed below or would you like to update the affiliation.

Khawla Badwan: Manchester Metropolitan University, UK 